\title{
Near-infrared calibration models for estimating volatile fatty acids and methane production from in vitro rumen fermentation of different total mixed rations
}

\author{
F. Ghilardelli, (1) G. Ferronato, (1) and A. Gallo* (1)
}

\section{Graphical Abstract}
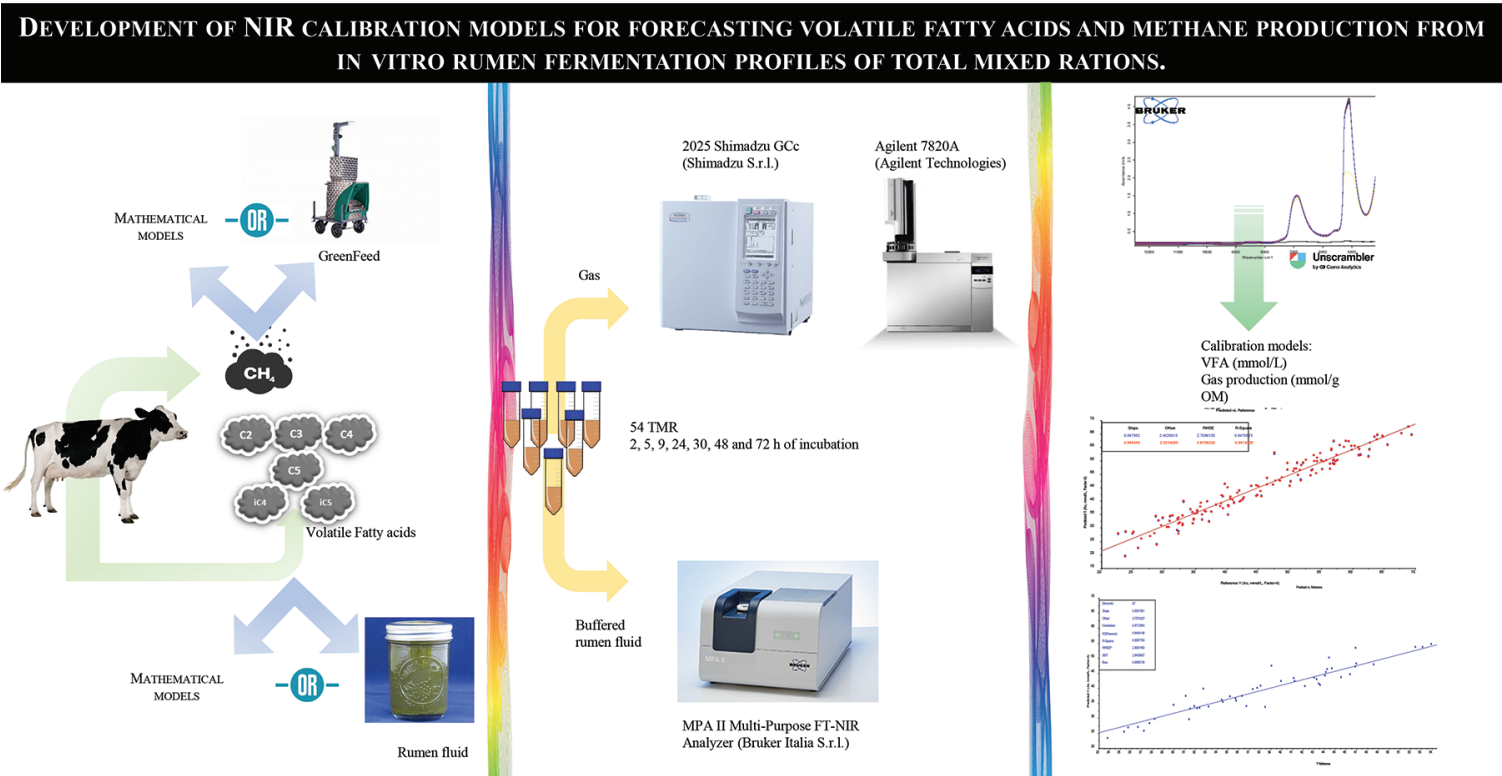

The proposed calibrations could be an alternative method in order to overcome costs and the use of animals in in vivo studies.

\section{Summary}

Diverse disciplines of science use near-infrared (NIR) spectroscopy for chemical analysis because it is rapid and inexpensive, and it provides reproducible results. Many animal scientists perform in vitro rumen fermentation tests to measure the production of volatile fatty acids (VFA) and methane (indicative of energy loss) from different feeds or diets. We used NIR spectroscopy to develop calibration models that predict the production of different VFA (acetic, propionic, butyric, valeric, isovaleric, and isobutyric acids), total gas, and methane from in vitro rumen fermentation of different silage-based diets. Our models provided reliable estimates of these rumen fermentation products.

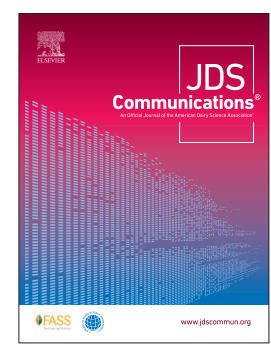

\section{Highlights}

- Near-infrared (NIR) prediction models accurately predicted volatile fatty acids, methane, and gas production.

- $\quad$ Outputs of models could provide useful information for calibrating rumen mechanistic models.

- Calibrations of valeric and isovaleric acids need to be improved. 


\title{
Near-infrared calibration models for estimating volatile fatty acids and methane production from in vitro rumen fermentation of different total mixed rations
}

\author{
F. Ghilardelli, $\odot$ G. Ferronato, $\odot$ and A. Gallo* $\odot$
}

\begin{abstract}
Volatile fatty acids (VFA) and methane $\left(\mathrm{CH}_{4}\right)$ are the major products of rumen fermentation. The VFA are considered an energy source for the animal and rumen microbiota, and $\mathrm{CH}_{4}$ (which is released by eructation) is considered an energy loss. Quantification of these fermentation products is fundamental for the evaluation of feeds and diets, and provides important information regarding the use of nutrients by ruminants. Near-infrared (NIR) spectroscopy is increasingly used for the evaluation of animal feeds because it is rapid, nondestructive, noninvasive, and inexpensive; does not require reagents; and the results are reproducible. The aim of this study was to develop NIR calibration models for estimating the production of VFA (acetic, propionic, butyric, valeric, isovaleric, and isobutyric acids), total gas, and $\mathrm{CH}_{4}$ using in vitro gas production tests with buffered rumen inoculum throughout fermentation. Fifty-four total mixed rations (TMRs) were examined, and rumen fluid was manually collected from 2 dry Holstein dairy cows that had ruminal fistulas and were fed at maintenance energy levels. Then, $30 \mathrm{~mL}$ of buffered rumen fluid was incubated in bottles with $\sim 220 \mathrm{mg}$ of TMR. The total gas, VFA, and $\mathrm{CH}_{4}$ were measured after 2, 5, 9, 24, 30, 48, and $72 \mathrm{~h}$ of rumen incubation for each TMR. The VFA were measured on 32 randomly selected TMR. In particular, 7 bottles were used for each TMR, one for each incubation time. Methane was measured in the headspace and VFA were measured in the buffered rumen fluid. The bottles were considered experimental units for calibration purposes. The production of $\mathrm{CH}_{4}$ was quantified from the bottle headspaces by gas chromatography, and total gas production was measured using a pressure transducer at each incubation time. Two aliquots of the fermented liquids were sampled by opening the bottles at each incubation time, and (1) the concentrations of VFA were determined by gas chromatography or (2) spectra were obtained from Fourier-transform NIR spectroscopy. The data were randomly divided into calibration and validation data sets. The average concentrations of acetic acid $(45.30 \pm 11.92$ and $43.86 \pm 11.93 \mathrm{mmol} / \mathrm{L})$, propionic acid $(14.97 \pm 6.08$ and $14.38 \pm 6.56 \mathrm{mmol} / \mathrm{L})$, butyric acid $(8.47 \pm 3.47$ and 8.65 $\pm 3.79 \mathrm{mmol} / \mathrm{L})$, total gas $\left(111.34 \pm 81.90\right.$ and $116.46 \pm 82.44 \mathrm{~mL} / \mathrm{g}$ of organic matter), and $\mathrm{CH}_{4}(9.65 \pm 9.45$ and $10.35 \pm 9.33 \mathrm{mmol} / \mathrm{L})$ were similar in the 2 data sets. The best calibration models were retained based on the coefficient of determination $\left(\mathrm{R}^{2}\right)$ and the ratio of prediction to deviation (RPD). The $\mathrm{R}^{2}$ values for prediction of VFA ranged from $0.69(\mathrm{RPD}=3.28)$ for valeric acid to $0.94(\mathrm{RPD}=$ 4.20) for acetic acid. The models also provided good predictions of $\mathrm{CH}_{4}\left(\mathrm{R}^{2}=0.89, \mathrm{RPD}=3.05\right)$ and cumulative gas production $\left(\mathrm{R}^{2}=\right.$ $0.91, \mathrm{RPD}=3.30$ ). The models described here precisely and accurately estimated the production of $\mathrm{CH}_{4}$ and VFA during in vitro rumen fermentation tests. Validations at additional laboratories may provide more robust calibrations.
\end{abstract}

V olatile fatty acids are the main products of rumen fermentation, and represent about 40 to $70 \%$ of digestible energy intake (Dijkstra et al., 2005). The proportions of acetic, butyric, and propionic acids from rumen fermentation determine the amount of hydrogen $\left(\mathrm{H}_{2}\right)$ available for methanogenic bacteria (Alemu et al., 2011). In contrast, methane $\left(\mathrm{CH}_{4}\right)$ production results from microbial digestion, and ruminants expel $\mathrm{CH}_{4}$ by belching (eructation). The production of $\mathrm{CH}_{4}$ indicates an energy loss for ruminants (Ellis et al., 2008) because it decreases the efficiency of the feed use, and it also contributes to global warming (Rossi et al., 2001). Several approaches that use mathematical models or direct laboratory methods can quantify rumen $\mathrm{CH}_{4}$ and VFA productions. The molar proportions of VFA in the rumen are the consequence of differences in the rate of production, interconversion, and absorption (Morvay et al., 2011). Thus, researchers use stoichiometric coefficients (Bannink et al., 2006) in mechanistic models of the rumen to estimate VFA production. In addition, individual VFA in rumen can be directly determined using GC of samples (Cottyn and Boucque, 1968). The $\mathrm{CH}_{4}$ can also be quantified using mathematical models or direct measurements (Negussie et al., 2017), and indirect estimates can be from empirical or process-based mechanistic models.

The development and use of these equations requires measurements of many parameters in different conditions (e.g., physiological stage of the animal, feeding strategy, DMI) to achieve high prediction accuracy (Patra, 2016). The most commonly used techniques for direct analysis are respiration chambers, the sulfur hexafluoride $\left(\mathrm{SF}_{6}\right)$ tracer method, and the automated head-chamber system (i.e., GreenFeed). These all provide reliable measurements but are not suitable for large-scale applications (Patra, 2016). 
Alternatively, in vitro methods that measure gas production by buffered rumen inoculum can be used to estimate ruminant feedstuff value, characterize rumen fermentation dynamics, and measure $\mathrm{CH}_{4}$ production over time (Serment et al., 2016). Under controlled conditions, these in vitro methods quantify VFA and $\mathrm{CH}_{4}$ at different times, and these measurements are inexpensive to acquire and provide reproducible results. Getachew et al. (2005) reported that in vitro and in vivo techniques yielded similar measurements of $\mathrm{CH}_{4}$ production, although the scientific literature has contradictory results regarding the agreement of data from these different methods (Maccarana et al., 2016). In addition, Bhatta et al. (2006) compared results from the in vivo $\mathrm{SF}_{6}$ method with those from the in vitro rumen simulation technique (i.e., RUSITEC) and the in vitro gas production technique. They concluded that methane estimation using the gas production technique was very close to that measured by the in vivo technique, and the average coefficients of determination ranged from 0.92 to 0.99 , depending on the diet. Recently, Danielsson et al. (2017) compared $\mathrm{CH}_{4}$ production measured by the GreenFeed system and gas production for 49 different diets. These authors reported a coefficient of determination of 0.96 when in vitro data were used to predict in vivo $\mathrm{CH}_{4}$ emission.

To avoid the need for an in vivo trial, some mechanistic models simulating the rumen ecosystem have provided results that successfully reproduced rumen fermentation pathways. Recently, Muñoz-Tamayo et al. (2016) proposed a mechanistic rumen model that considered microbial metabolisms, acid-base reactions, and liquid-gas transfers based on in vitro data from Serment et al. (2016). These researchers subsequently validated this mechanistic model using an external data set, with in vitro data on VFA and $\mathrm{CH}_{4}$ production obtained by rumen fermentation of high-silage diets (Muñoz-Tamayo et al., 2019). A critical consideration for the accurate representation of the rumen ecosystem when using these models is the availability of data for model calibration and validation. Near-infrared (NIR) spectroscopy is an inexpensive and simple technique that can potentially provide these data.

Animal scientists who study livestock and feed evaluation are increasingly using NIR spectroscopy. The advantages of this method are that it is rapid, it does not require reagents, it is nondestructive and noninvasive, and it provides reproducible results at very low cost. Some researchers have used infrared calibration in the nearor mid-infrared (MIR) regions to measure many different biologic substrates (Yakubu et al., 2020). In the NIR region, the peaks are overtones and combination peaks of molecular vibrations. These nonfundamental excitations are weaker than the fundamental bands and arise from the $\mathrm{O}-\mathrm{H}, \mathrm{C}-\mathrm{H}, \mathrm{S}-\mathrm{H}$, and $\mathrm{N}-\mathrm{H}$ stretching modes (Zhang et al., 2009). The main constraints for obtaining accurate calibration models are the accuracy, variability, and distribution of the primary data, as well as the concentration and physical structure of the chemical compounds and types of samples. Despite these limitations, Zhang et al. (2021) successfully used NIR spectroscopy to evaluate single feed or TMR chemical composition and in situ disappearance, and other researchers successfully used NIR spectroscopy to measure in vitro digestibility (Andrés et al., 2005; Mentink et al., 2006). However, little information is available on the accuracy of the NIR method for predicting the production of total gas, VFA, and $\mathrm{CH}_{4}$ from a rumen fluid sample.

The aim of this study was to assess the use of NIR calibration models to determine the major rumen fermentation parameters by direct analysis of fermented buffered rumen fluids. The specific fermentation products produced by incubating TMR in vitro with a buffered rumen fluid collected from fistulated animals were VFA (acetic, propionic, butyric, valeric, isovaleric and isobutyric acids), total gas, and $\mathrm{CH}_{4}$.

A total of 54 TMR were collected from dairy farms in the Po valley of northern Italy during 2018. Details regarding locations of dairy farms and TMR sampling technique were previously reported (Atzori et al., 2021). These TMR were dried in a $65^{\circ} \mathrm{C}$ forced-air oven to constant weight, and then ground to a particle size of $1 \mathrm{~mm}$ in a rotor speed laboratory mill (Pulverisette 19). For in vitro gas production tests, a sample $(\sim 220 \mathrm{mg})$ was added into a $100-\mathrm{mL}$ glass bottle (Gallo et al., 2016). Each experimental run consisted of 18 TMR that were incubated together. There were 7 replicates of each TMR sample, 1 for each incubation time. In addition, 4 bottles with only buffered rumen fluid (blanks) and 4 bottles with a starch sample (internal standard, Gelose 80 maize starch; Penford Food Ingredients Co.) were incubated in each experimental run. Blanks and internal standards were used to verify gas production dynamics of each run. Indeed, the cumulative blanks or internal standard gas production of all fermentation runs performed in the experiment had to be within the average value \pm 1 standard deviation to be considered acceptable. If this condition was not met, the run was repeated.

A buffer-mineral solution (Menke and Steingass, 1988) was prepared on the same day as inoculation, and it was added to a water bath at $39^{\circ} \mathrm{C}$ under continuous $\mathrm{CO}_{2}$ flushing to create anaerobic conditions. The $\mathrm{pH}$ was adjusted to 6.5 to 6.6 . Rumen fluids were manually collected from 2 Holstein dry dairy cows that had ruminal fistulas (BW $625 \pm 10 \mathrm{~kg}$ ) and were maintained at the CERZOO experimental station (San Bonico, Piacenza, Italy). These cows received maintenance diets, and rumen samples were collected after the morning feeding (NRC, 2001). The TMR had $12 \% \mathrm{CP}$ and $55 \% \mathrm{NDF}$, determined by using amylase and sodium sulfite, on a DM basis, and consisted of grass hay ( $75 \% \mathrm{DM})$, corn silage $(15 \%$ $\mathrm{DM})$, and a protein vitamin mineral supplement $(10 \% \mathrm{DM})$. On the day of rumen collection, the rumen fluid inoculum was transferred into 2 warmed thermos flasks, combined, filtered through 2 layers of cheesecloth, added to the buffered mineral solution, and then maintained at $39^{\circ} \mathrm{C}$ in a water bath and flushed with $\mathrm{CO}_{2}$. The rumen inoculum was maintained in a warm insulated flask and used within 20 min of sampling. The rumen inoculum was then diluted ( $1: 2 \mathrm{vol} / \mathrm{vol}$ rumen fluid:buffer-mineral solution) and the buffered rumen mixture was maintained in continuous agitation, at constant temperature, and under anaerobic conditions. As described by Pirondini et al. (2012) and Serment et al. (2016) with minor modifications, about $30 \mathrm{~mL}$ of diluted rumen fluid was transferred into each bottle containing the TMR. First, the bottle headspace (70-mL volume) was flushed with $\mathrm{CO}_{2}$ and the bottle was then hermetically closed with rubber caps and degassed. The headspace pressure was recorded after 2, 5, 9, 24, 30, 48, and $72 \mathrm{~h}$ using a gas pressure transducer (digital test gauge XP2i, Crystal Engineering Corp.). The remaining gas was then released by puncturing the cap with a needle, and the pressure was brought back to atmospheric level. To preserve normal microbial activity, the headspace pressure never exceeded $48 \mathrm{kPa}$, as recommended by Theodorou et al. (1994). The gas pressure results were converted to moles of gas using the ideal gas law: 


$$
n=p \times V /(R \times T),
$$

where $n$ is moles of gas, $p$ is pressure $(\mathrm{kPa}), V$ is headspace volume (L), $R$ is the gas constant $\left(8.314 \mathrm{~L} \cdot \mathrm{kPa} \cdot \mathrm{K}^{-1} \cdot \mathrm{mol}^{-1}\right)$, and $T$ is temperature $(\mathrm{K})$.

One bottle that contained substrate and fermented liquid was used at each incubation time to measure $\mathrm{CH}_{4}$ in the headspace and VFA concentrations in the buffered rumen inoculum. For this procedure, the bottle was put on ice to stop fermentation, and $1 \mathrm{~mL}$ of headspace gas was then sampled using a $2-\mathrm{mL}$ gas-tight glass syringe with a pressure lock (VICI, Precision Sampling Inc.) to collect a sample. This $1-\mathrm{mL}$ sample of gas was analyzed using a GC system (Agilent 7820A, Agilent Technologies) using $\mathrm{N}_{2}$ as a carrier. An external standard mixture of $\mathrm{CO}_{2}$ and $\mathrm{CH}_{4}$ prepared by SIAD S.p.A. (Bergamo, Italy) was used for instrument calibration. Peak areas were calculated by automatic integration. The amount of $\mathrm{CH}_{4}(\mathrm{mmol})$ produced between adjacent time points and the final amount were calculated as described by Tavendale et al. (2005).

Then, 2 aliquots of fermented rumen fluid were stored at $-20^{\circ} \mathrm{C}$ and used for measurements by 2 different methods. In the first
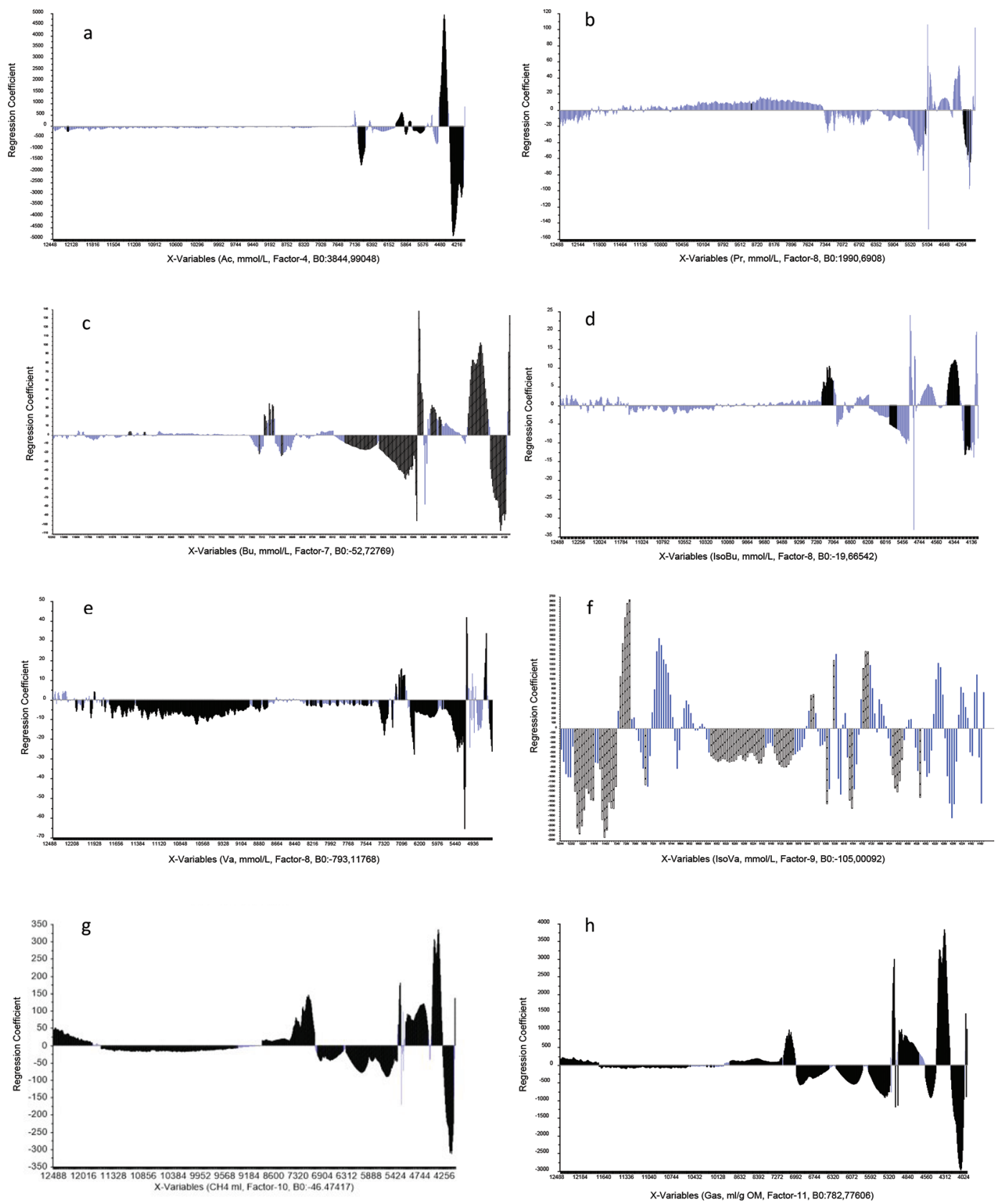

Figure 1. Selection of latent variables for each partial least squares model: (a) acetic acid; (b) propionic acid; (c) butyric acid; (d) isobutyric acid; (e) valeric acid; (f) isovaleric acid; (g) methane; and (h) total gas. 
Table 1. Levels of in vitro rumen fermentation products in the calibration and validation data sets

\begin{tabular}{|c|c|c|c|c|c|c|c|c|c|c|}
\hline \multirow[b]{2}{*}{ Fermentation product } & \multicolumn{4}{|c|}{ Calibration data } & \multirow[b]{2}{*}{$\mathrm{CV}$} & \multicolumn{4}{|c|}{ Validation data } & \multirow[b]{2}{*}{ CV } \\
\hline & Mean & Maximum & Minimum & SD & & Mean & Maximum & Minimum & SD & \\
\hline Acetic acid, mmol/L & 45.30 & 69.41 & 22.69 & 11.92 & 0.26 & 43.86 & 64.56 & 23.81 & 11.93 & 0.27 \\
\hline Propionic acid, mmol/L & 14.97 & 33.15 & 3.77 & 6.08 & 0.41 & 14.38 & 32.92 & 5.47 & 6.56 & 0.46 \\
\hline Butyric acid, $\mathrm{mmol} / \mathrm{L}$ & 8.47 & 16.79 & 2.22 & 3.47 & 0.41 & 8.65 & 19.70 & 1.75 & 3.79 & 0.44 \\
\hline Valeric acid, $\mathrm{mmol} / \mathrm{L}$ & 1.00 & 3.07 & 0.15 & 0.62 & 0.62 & 1.01 & 3.15 & 0.16 & 0.69 & 0.69 \\
\hline Isobutyric acid, $\mathrm{mmol} / \mathrm{L}$ & 0.60 & 2.10 & 0.15 & 0.35 & 0.59 & 0.67 & 2.11 & 0.22 & 0.44 & 0.66 \\
\hline Isovaleric acid, mmol/L & 0.93 & 3.51 & 0.22 & 0.63 & 0.67 & 0.90 & 1.83 & 0.30 & 0.49 & 0.54 \\
\hline Methane, $\mathrm{mmol} / \mathrm{L}$ & 9.65 & 33.94 & 0.02 & 9.45 & 0.98 & 10.35 & 32.30 & 0.01 & 9.33 & 0.90 \\
\hline Total gas, $\mathrm{mL} / \mathrm{g}$ of $\mathrm{OM}$ & 111.34 & 276.89 & 0.01 & 81.90 & 0.74 & 116.46 & 280.63 & 0.01 & 82.44 & 0.71 \\
\hline
\end{tabular}

method, VFA concentrations were determined using a GC system (2025 Shimadzu GC, Shimadzu S.r.1.). This device had an autosampler (AOC-20i Shimadzu S.r.1.), flame-ionization detector, and capillary column (DB-FFAP; $30 \mathrm{~m}, 0.250 \mathrm{~mm}, 0.25 \mu \mathrm{m}$; Agilent Technologies S.p.A.). The injector operated at $200^{\circ} \mathrm{C}$ and the detector at $220^{\circ} \mathrm{C}$. The injection volume was $1 \mu \mathrm{L}$ and the split ratio was 100:1. In the second method, Fourier-transform (FT)-NIR spectroscopy of samples was performed using an MPA II MultiPurpose FT-NIR Analyzer (Bruker Italia S.r.l. Unipersonale). Before this analysis, the buffered rumen fluid was thawed at $37^{\circ} \mathrm{C}$ in a water bath for $15 \mathrm{~min}$, cooled in a water and ice solution, centrifuged at $3,800 \times g$ for $16 \mathrm{~min}$ at $6^{\circ} \mathrm{C}$, and placed in a thermostatically controlled water bath at $30^{\circ} \mathrm{C}$ for $10 \mathrm{~min}$. All spectra were acquired in duplicate. The flow cell thermostat was set to $30^{\circ} \mathrm{C}$ and the resolution was $8 \mathrm{~cm}^{-1}$ in the range of 12,488 to $4,000 \mathrm{~cm}^{-1}$. For methane, a primary database was created and measurements were recorded from each bottle of each fermented TMR. There were 378 observations ( 7 bottles for each of the 54 TMR). For measurements of gas production, results were obtained on all remaining unopened bottles at each incubation time. For VFA, 32 randomly selected TMR were sampled and used to generate measurements for NIR calibrations. The databases were analyzed to determine fermentation parameters and NIR spectra using a statistical filtering procedure, based on univariate and multivariate approaches. The detection of outliers in the primary data was determined using the threshold technique of calculating an acceptability range:

$$
\text { Threshold }_{\min }=\text { mean }-a \times \mathrm{SD} ; \text { Threshold }_{\max }=\text { mean }+a \times \mathrm{SD} \text {, }
$$

where the control parameter (a) was set to 2 (Yang et al., 2019). Then, principal component analysis (PCA) was used to analyze spectra and detect outliers according the influence plot, based on Hoteling's $T^{2}$ statistic with a $5 \%$ limit. The acquired spectra were processed by Unscrambler X software (version 10.5.1, CAMO Software) for development of calibration curves using partial least squares (PLS) fitting. In particular, spectra were randomly assigned to a calibration set or a validation set in a 70:30 ratio. Different preprocessing methods were used to remove physical variations in the spectra (Rinnan et al., 2009). These methods corrected for scatter (standard normal variate method) and spectral derivation (Savitzky-Golay polynomial derivative method). Using the calibration set, a PLS regression model with a cross-validation leave-one-out criterion and a nonlinear iterative PLS (NIPALS) algorithm were performed using NIR wavelengths as the predic- tor terms. To avoid redundancy and collinearity and improve the robustness of the calibration models, specific NIR spectral regions were selected according to an optimal number of latent variables (Gowen et al., 2011). In this procedure, the software set the residual variance to quantify the effect of adding an additional factor to the model on the increase of $\mathrm{R}^{2}$ (Figure 1 ). An $\mathrm{R}^{2}$ value close to 1 indicates good linear dependence between the observed and predicted values; that is, good predictability of the model (Sileoni et al., 2013). If the variance between 2 consecutive factors was less than $6 \%$, the latent factor extraction process was stopped and the model was developed using the optimal number of factors (Tian et al., 2021). All regression models were then applied to the validation set to determine the accuracy of predictions. In particular, the accuracy of the models was evaluated by calculating the coefficient of determination $\left(\mathrm{R}^{2}\right)$, the root mean square error, the standard error of calibration, the standard error of cross-validation, the standard error of prediction (SEP), and the ratio of prediction to deviation (RPD). The models that provided the best predictions were retained (Aptula et al., 2005).

We first calculated the means, SD, ranges, and coefficients of variation $(\mathbf{C V})$ for data on the production of VFA, $\mathrm{CH}_{4}$, and total gas for the calibration and validation data sets (Table 1). The calibration set had the greatest $\mathrm{CV}$ for isobutyric acid (0.59), isovaleric acid (0.67), valeric acid (0.62), $\mathrm{CH}_{4}(0.98)$, and total gas (0.74). The average concentration between calibration and validation sets of acetic acid was $44.58 \pm 1.92 \mathrm{mmol} / \mathrm{L}$, the average of propionic acid was $14.64 \pm 6.32 \mathrm{mmol} / \mathrm{L}$, and the average of butyric acid was $8.56 \pm 3.63 \mathrm{mmol} / \mathrm{L}$. The wide range in these concentrations was related to the different fermentation times (rumen sampling times).

We assessed the performance of prediction models using NIR data for each parameter (Table 2). The prediction of VFA levels could be considered satisfactory, in that the $\mathrm{R}^{2}$ ranged from 0.69 $(\mathrm{SEP}=0.21 \mathrm{mmol} / \mathrm{L})$ for valeric acid to $0.94(\mathrm{SEP}=2.84 \mathrm{mmol} / \mathrm{L})$ for acetic acid. The model also provided good predictions for $\mathrm{CH}_{4}$ $\left(\mathrm{R}^{2}=0.89, \mathrm{SEP}=3.06 \mathrm{mmol} / \mathrm{L}\right)$ and total cumulative gas production $\left(\mathrm{R}^{2}=0.91, \mathrm{SEP}=24.99 \mathrm{~mL} / \mathrm{g}\right.$ of $\left.\mathrm{OM}\right)$ as measured from $2 \mathrm{~h}$ to $72 \mathrm{~h}$ of rumen incubations. Williams (2001) recommends an RPD value $>3$ to define a predictive model as excellent. Thus, all of our models were excellent except the model for isovaleric acid (RPD $=1.95$, Table 2). In particular, the low RPD for isovaleric acid suggests that our method can simply distinguish between high and low values, and that a more accurate NIR spectroscopy calibration must be used for this branched VFA.

Only a few previous studies reported calibration models to predict VFA and $\mathrm{CH}_{4}$ from direct analysis of rumen fluid from NIR spectroscopy. For example, Turza et al. (2002) found that NIR 
spectroscopy had the potential to properly predict rumen fluid composition when a specially designed fiber optic method was used. In particular, their predictive models achieved satisfactory results, with $\mathrm{R}^{2}$ values ranging from 0.81 (isobutyric acid) to 0.92 (acetic acid). The performance of our predictive models for acetic, butyric, valeric, and isobutyric acids were in line these previous results. Our models had lower $\mathrm{R}^{2}$ values for propionic acid $(0.81)$ and isovaleric acid $(0.73)$ than did the models reported by Turza et al. (2002). These differences could be attributable to the greater variation of the primary data used in our validation and calibration data sets.

Udén and Sjaunja (2009) developed rumen fermentation models to predict acetate, propionate, and butyrate, and reported satisfactory accuracy. Specifically, they analyzed 308 samples for calibration using FT-MIR spectroscopy of samples of semi-artificial rumen fluids that were spiked with acetate, propionate, and butyrate, with and without bicarbonate and phosphate. Tagliapietra et al. (2015) analyzed in vitro rumen fermentation fluid using FT-MIR spectroscopy with Bayesian models and reported similar accuracy in their predictive models. In particular, these researchers developed different VFA calibration models using 8 diets for lactating cows that differed in the content of fiber, CP, lipids, and starch. These diets were fermented for specific times (24 and $48 \mathrm{~h}$ ) and there were 4 different in vitro incubations. Their results for acetic acid $\left(\mathrm{R}^{2}=0.92\right)$ and butyric acid $\left(\mathrm{R}^{2}=0.84\right)$ were similar to our results, but they reported better results for the other VFA (propionic acid: $\mathrm{R}^{2}=0.90$; isobutyric acid: $\mathrm{R}^{2}=0.91$, isovaleric acid: $\mathrm{R}^{2}=0.93$, valeric acid: $\mathrm{R}^{2}=0.91$ ). This could be due to their use of different spectral regions in the predictive models. In particular, absorbance in the MIR region is directly related to the concentration of individual compounds, but absorbance in the NIR region results from overtones and their combinations (Udén and Sjaunja, 2009).

Zhang et al. (2009) developed an FT-NIR calibration for VFA and ethanol in the effluent of an anaerobic $\mathrm{H}_{2}$-producing bioreactor. Generally, the discriminant absorption bands in calibration models are related to the frequencies of the third overtone of $\mathrm{C}-\mathrm{H}$ bonds and the second overtone of $\mathrm{O}-\mathrm{H}$ bonds, to the first overtone of C-H combinations $\left(7,200-6,100 \mathrm{~cm}^{-1}\right.$ and $\left.6,100-5,400 \mathrm{~cm}^{-1}\right)$ and the first overtone of $\mathrm{O}-\mathrm{H}$ bonds $\left(7,200-6,100 \mathrm{~cm}^{-1}\right)$, and to $\mathrm{C}-\mathrm{H}$ bond combinations and $\mathrm{C}-\mathrm{H}$ and $\mathrm{O}-\mathrm{H}$ combinations $(4,900-4,100$ $\mathrm{cm}^{-1}$ ), consistent with our results (Figure 1). Previous studies used NIR spectroscopy to predict the kinetics of in vitro fermentation of dairy cow feed for hay, but the results were unsatisfactory (Herrero et al., 1997; Andrés et al., 2005). Another study (Lovett et al., 2004) reported moderately successful results for silage. Our predictive models had good performance and low error in the calibration and validation data sets.

Critically, the present study should be considered a preliminary evaluation of the use of NIR spectroscopy to predict the production of $\mathrm{CH}_{4}$ and VFA from in vitro rumen fermentation. We suggest that future calibrations should be performed by organizing specific collaborative interlaboratory experiments to improve the applicability to research and commercial laboratories. For each diet, we used 7 different bottles for measurements at 7 incubation times to generate profiles of VFA and $\mathrm{CH}_{4}$, in line with the method previously adopted by Serment et al. (2016). We considered each bottle a separate experimental unit, although some of these bottles con-

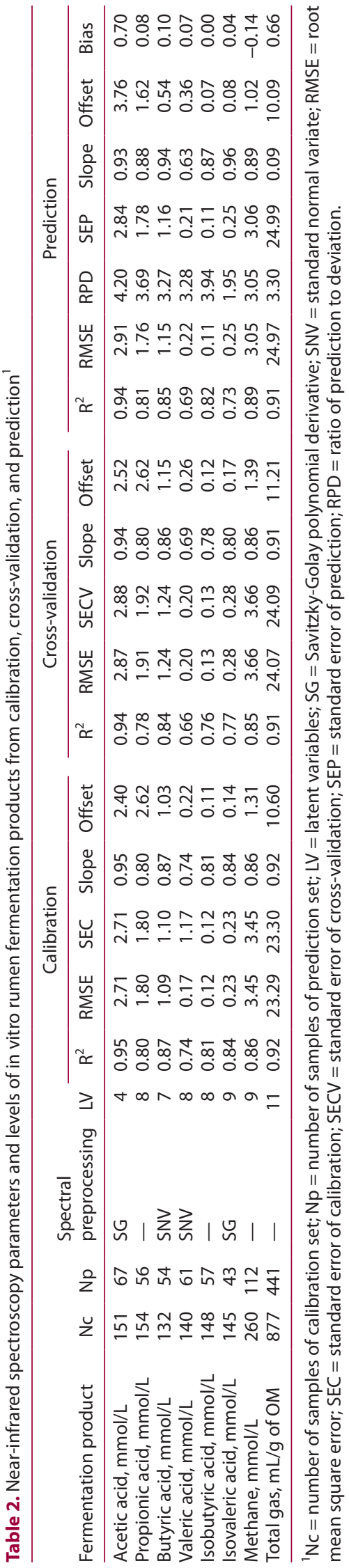


tained the same TMR and were incubated with the same buffered rumen fluid. We know that a further step of intra- or interlaboratory calibration development should be done by analyzing additional TMR to be more representative of different nutritional strategies, environmental conditions, and production systems.

In conclusion, the NIR spectroscopy models presented here provided good predictions of the production of VFA, total gas, and methane from in vitro fermentation of rumen fluid. The outputs of these models could provide useful information for calibrating rumen mechanistic models that simulate the ruminal compartment of dairy cows, with the notable advantages that NIR spectroscopy is rapid and inexpensive. However, it is important to improve the calibrations for valeric acid and isovaleric acid to obtain more accurate NIR models for these VFA.

\section{References}

Alemu, A. W., J. Dijkstra, A. Bannink, J. France, and E. Kebreab. 2011. Rumen stoichiometric models and their contribution and challenges in predicting enteric methane production. Anim. Feed Sci. Technol. 166-167:761-778. https://doi.org/10.1016/j.anifeedsci.2011.04.054.

Andrés, S., A. Calleja, S. López, J.S. González, P.L. Rodríguez, and F.J. Giráldez. 2005. Prediction of gas production kinetic parameters of forages by chemical composition and near infrared reflectance spectroscopy. Anim. Feed Sci. Technol. 123-124:487-499. https://doi.org/10.1016/j.anifeedsci 2005.04.043.

Aptula, A. O., N. G. Jeliazkova, T. W. Schultz, and M. T. D. Cronin. 2005. The better predictive model: High q2 for the training set or low root mean square error of prediction for the test set? QSAR Comb. Sci. 24:385-396. https://doi.org/10.1002/qsar.200430909.

Atzori, A. S., C. Valsecchi, E. Manca, F. Masoero, A. Cannas, and A. Gallo, 2021. Assessment of feed and economic efficiency of dairy farms based on multivariate aggregation of partial indicators measured on field. J. Dairy Sci. 104:12679-12692. https://doi.org/10.3168/jds.2020-19764.

Bannink, A., J. Kogut, J. Dijkstra, J. France, E. Kebreab, A. M. Van Vuuren, and S. Tamminga. 2006. Estimation of the stoichiometry of volatile fatty acid production in the rumen of lactating cows. J. Theor. Biol. 238:36-51. https: //doi.org/10.1016/j.jtbi.2005.05.026.

Bhatta, R., K. Tajima, N. Takusari, K. Higuchi, O. Enishi, and M. Kurihara. 2006. Comparison of sulfur hexafluoride tracer technique, rumen simulation technique and in vitro gas production techniques for methane production from ruminant feeds. Int. Congr. Ser. 1293:58-61. https://doi.org/10 $.1016 /$ j.ics.2006.03.075.

Cottyn, B. G., and C. V. Boucque. 1968. Rapid method for the gas-chromatographic determination of volatile fatty acids in rumen fluid. J. Agric. Food Chem. 16:105-107. https://doi.org/10.1021/jf60155a002.

Danielsson, R., M. Ramin, J. Bertilsson, P. Lund, and P. Huhtanen. 2017. Evaluation of a gas in vitro system for predicting methane production in vivo. J. Dairy Sci. 100:8881-8894. https://doi.org/10.3168/jds.2017-12675.

Dijkstra, J., J. M. Forbes, and J. France. 2005. Quantitative Aspects of Ruminant Digestion and Metabolism. 2nd ed. CABI Publishing.

Ellis, J. L., J. Dijkstra, E. Kebreab, A. Bannink, N. E. Odongo, B. W. McBride, and J. France. 2008. Aspects of rumen microbiology central to mechanistic modelling of methane production in cattle. J. Agric. Sci. 146:213-233. https://doi.org/10.1017/S0021859608007752.

Gallo, A., G. Giuberti, and F. Masoero. 2016. Gas production and starch degradability of corn and barley meals differing in mean particle size. J. Dairy Sci. 99:4347-4359. https://doi.org/10.3168/jds.2015-10779.

Getachew, G., E. J. DePeters, P. H. Robinson, and J. G. Fadel. 2005. Use of an in vitro rumen gas production technique to evaluate microbial fermentation of ruminant feeds and its impact on fermentation products. Anim. Feed Sci. Technol. 123-124:547-559. https://doi.org/10.1016/j.anifeedsci.2005 .04 .034 .

Gowen, A. A., G. Downey, C. Esquerre, and C. P. O’Donnell. 2011. Preventing over-fitting in PLS calibration models of near-infrared (NIR) spectroscopy data using regression coefficients. J. Chemometr. 25:375-381. https://doi .org/10.1002/cem.1349.

Herrero, M., N. S. Jessop, R. H. Fawcett, I. Murray, and J. B. Dent. 1997. Prediction of the in vitro gas production dynamics of kikuyu grass by near-infrared reflectance spectroscopy using spectrally-structured sample populations. Anim. Feed Sci. Technol. 69:281-287. https://doi.org/10 .1016/S0377-8401(97)81642-2.

Lovett, D. K., E. R. Deaville, F. Mould, D. I. Givens, and E. Owen. 2004. Using near infrared reflectance spectroscopy (NIRS) to predict the biological parameters of maize silage. Anim. Feed Sci. Technol. 115:179-187. https:/ /doi.org/10.1016/j.anifeedsci.2004.02.007.

Maccarana, L., M. Cattani, F. Tagliapietra, S. Schiavon, L. Bailoni, and R. Mantovani. 2016. Methodological factors affecting gas and methane production during in vitro rumen fermentation evaluated by meta-analysis approach. J. Anim. Sci. Biotechnol. 7:35. https://doi.org/10.1186/s40104-016-0094-8.

Menke, K. H., and H. Steingass. 1988. Estimation of the energetic feed value obtained from chemical analysis and in vitro gas production using rumen fluid. Anim. Res. Dev. 28:7-55.

Mentink, R. L., P. C. Hoffman, and L. M. Bauman. 2006. Utility of nearinfrared reflectance spectroscopy to predict nutrient composition and in vitro digestibility of total mixed rations. J. Dairy Sci. 89:2320-2326. https: //doi.org/10.3168/jds.S0022-0302(06)72303-7.

Morvay, Y., A. Bannink, J. France, E. Kebreab, and J. Dijkstra. 2011. Evaluation of models to predict the stoichiometry of volatile fatty acid profiles in rumen fluid of lactating Holstein cows. J. Dairy Sci. 94:3063-3080. https:/ /doi.org/10.3168/jds.2010-3995.

Muñoz-Tamayo, R., A. S. Atzori, A. Cannas, F. Masoero, S. Giger-Reverdin, D. Sauvant, and A. Gallo. 2019. Assessing the predictive capabilities of a dynamic mechanistic model of in vitro rumen fermentation and methane production. In Proc. 9th Workshop on Modelling Nutrient Digestion and Utilization in Farm Animals (MODNUT). Adv. Anim. Biosci. 10:285-367. https://doi.org/10.1017/S2040470019000025

Muñoz-Tamayo, R., S. Giger-Reverdin, and D. Sauvant. 2016. Mechanistic modelling of in vitro fermentation and methane production by rumen microbiota. Anim. Feed Sci. Technol. 220:1-21. https://doi.org/10.1016/j .anifeedsci.2016.07.005.

Negussie, E., Y. de Haas, F. Dehareng, R. J. Dewhurst, J. Dijkstra, N. Gengler, D. P. Morgavi, H. Soyeurt, S. van Gastelen, T. Yan, and F. Biscarini. 2017. Invited review: Large-scale indirect measurements for enteric methane emissions in dairy cattle: A review of proxies and their potential for use in management and breeding decisions. J. Dairy Sci. 100:2433-2453. https:// doi.org/10.3168/jds.2016-12030.

NRC. 2001. Nutrient Requirement of Dairy Cattle. 7th rev. ed. National Academies Press.

Patra, A. K. 2016. Recent advances in measurement and dietary mitigation of enteric methane emissions in ruminants. Front. Vet. Sci. 3:39. https://doi .org/10.3389/fvets.2016.00039.

Pirondini, M., L. Malagutti, S. Colombini, P. Amodeo, and G. M. Crovetto. 2012. Methane yield from dry and lactating cows diets in the Po plain (Italy) using an in vitro gas production technique. Ital. J. Anim. Sci. 11:e61. https://doi.org/10.4081/ijas.2012.e61.

Rinnan, Å., F. van den Berg, and S. B. Engelsen. 2009. Review of the most common pre-processing techniques for near-infrared spectra. Trends Analyt. Chem. 28:1201-1222. https://doi.org/10.1016/j.trac.2009.07.007.

Rossi, F., P. Vecchia, and F. Masoero. 2001. Estimate of methane production from rumen fermentation. Pages 89-92 in Nutrient Cycling in Agroecosystems. Springer.

Serment, A., S. Giger-Reverdin, P. Schmidely, O. Dhumez, L. P. Broudiscou, and D. Sauvant. 2016. In vitro fermentation of total mixed diets differing in concentrate proportion: Relative effects of inocula and substrates. J. Sci Food Agric. 96:160-168. https://doi.org/10.1002/jsfa.7076.

Sileoni, V., O. Marconi, G. Perretti, and P. Fantozzi. 2013. Evaluation of different validation strategies and long term effects in NIR calibration models. Food Chem. 141:2639-2648. https://doi.org/10.1016/j.foodchem.2013.04 110 .

Tagliapietra, F., G. Rossi, S. Schiavon, A. Ferragina, C. Cipolat-Gotet, and G. Bittante. 2015. Use of Fourier transform infrared (FTIR) spectroscopy to predict VFA and ammonia from In vitro rumen fermentation. Poljoprivreda (Osijek) 21(1 Suppl.):130-134. https://doi.org/10.18047/poljo.21.1.sup .30 .

Tavendale, M. H., L. P. Meagher, D. Pacheco, N. Walker, G. T. Attwood, and S. Sivakumaran. 2005. Methane production from in vitro rumen incubations with Lotus pedunculatus and Medicago sativa, and effects of extractable condensed tannin fractions on methanogenesis. Anim. Feed Sci. Technol. 123-124:403-419. https://doi.org/10.1016/j.anifeedsci.2005.04.037. 
Theodorou, M. K., B. A. Williams, M. S. Dhanoa, A. B. McAllan, and J. France. 1994. A simple gas production method using a pressure transducer to determine the fermentation kinetics of ruminant feeds. Anim. Feed Sci. Technol. 48:185-197. https://doi.org/10.1016/0377-8401(94)90171-6.

Tian, W., G. Chen, Y. Gui, G. Zhang, and Y. Li. 2021. Rapid quantification of total phenolics and ferulic acid in whole wheat using UV-Vis spectrophotometry. Food Control 123:107691. https://doi.org/10.1016/j.foodcont .2020 .107691

Turza, S., J. Y. Chen, Y. Terazawa, N. Takusari, M. Amari, and S. Kawano. 2002. On-line monitoring of rumen fluid in milking cows by fibre optics in transmittance mode using the longer NIR region. J. Near Infrared Spectrosc. 10:111-120. https://doi.org/10.1255/jnirs.328.

Udén, P., and L. O. Sjaunja. 2009. Estimating volatile fatty acid concentrations in rumen samples by Fourier transform mid-IR transmission spectroscopy. Anim. Feed Sci. Technol. 152:123-132. https://doi.org/10.1016/ j.anifeedsci.2009.04.002.

Williams, P. 2001. Chapter 8: Implementation of near-infrared technology. Pages 145-169 in Near-Infrared Technology in the Agricultural and Food Industries. 2nd ed. P. C. Williams and K. Norris, ed. American Association of Cereal Chemists.

Yakubu, H. G., Z. Kovacs, T. Toth, and G. Bazar. 2020. The recent advances of near-infrared spectroscopy in dairy production-A review. Crit. Rev. Food Sci. Nutr. 1-22. https://doi.org/10.1080/10408398.2020.1829540.
Yang, J., S. Rahardja, and P. Fränti. 2019. Outlier detection: How to threshold outlier scores? Pages 1-6 in Proc. Int. Conf. Artificial Intelligence, Information Processing and Cloud Computing. Association for Computing Machinery.

Zhang, G. J., Y. Wang, Y. H. Yan, M. H. Hall, D. J. Undersander, and D. K. Combs. 2021. Comparison of two in situ reference methods to estimate indigestible NDF by near infrared reflectance spectroscopy in alfalfa. Heliyon 7:e07313. https://doi.org/10.1016/j.heliyon.2021.e07313.

Zhang, M. L., G. P. Sheng, Y. Mu, W. H. Li, H. Q. Yu, H. Harada, and Y. Y. Li 2009. Rapid and accurate determination of VFAs and ethanol in the effluent of an anaerobic $\mathrm{H}_{2}$-producing bioreactor using near-infrared spectroscopy. Water Res. 43:1823-1830. https://doi.org/10.1016/j.watres.2009.01.018.

\section{Notes}

F. Ghilardelli (1) https://orcid.org/0000-0001-8631-1544

G. Ferronato (1) https://orcid.org/0000-0001-9153-8540

A. Gallo (1) https://orcid.org/0000-0002-4700-4450

Financial support was provided by Fondazione Romeo ed Enrica Invernizzi (Milan, Italy).

The authors have not stated any conflicts of interest. 